\title{
Failure Behaviour of Fe- and Co-Based Amorphous Soft Magnetic Ribbons
}

\author{
J. MišKuf, K. Csach, A. JuRÍkOvÁ \\ Institute of Experimental Physics, Slovak Academy of Sciences \\ Watsonova 47, 04001 Košice, Slovakia \\ G. JANÁK \\ Department of Materials Science, Metallurgical Faculty \\ Technical University Košice, Letná 9, 04200 Košice, Slovakia \\ T. ŠVEC AND M. KONČ \\ Institute of Physics, Faculty of Science, P.J. Šafárik University, \\ Park Angelinum 9, 04001 Košice, Slovakia

\begin{abstract}
Fractographic analysis of Co- and Fe-based high strength soft magnetic materials showed the high localization of the plastic deformation and the ductility in narrow shear bands. The estimated fracture toughness of these materials is closely associated with the scale of the local plastic zone.
\end{abstract}

PACS numbers: 61.43.Dq, 62.25.Mn

\section{Introduction}

The ultrahigh strength alloys exhibit simultaneously good soft magnetic properties: a low coercivity and an extremely high permeability $[1,2]$. In recent years new high strength Co- and Fe-based alloys with the fracture strength of $\approx 5$ and $4 \mathrm{GPa}$, respectively, were developed $[3,4]$. These amorphous metals usually exhibit very poor ductility $(<0.5 \%)$ that limits their applications. The enlarged temperature interval $T_{\mathrm{g}}-T_{x}$ gives the chance to modify the ductility of these metallic glasses. The aim of this work is the comparative study of the ductility of typical Fe- and Co-based high strength amorphous alloys.

\section{Experimental details}

The amorphous ribbons $\mathrm{Fe}_{65.9} \mathrm{Cr}_{11.6} \mathrm{Si}_{7.5} \mathrm{~B}_{15}$ and $\mathrm{Co}_{43} \mathrm{Ta}_{5.5} \mathrm{Fe}_{20} \mathrm{~B}_{31.5}$ (in at.\%) with the thickness of 40 and $45 \mu \mathrm{m}$, respectively, prepared by melt spinning 
method were used. The glass transition temperature $T_{\mathrm{g}}$ and the crystallization onset temperature $T_{x}$ were determined by differential scanning calorimetry (DSC) or differential thermal analysis (DTA). Vickers microhardness $H v$ was measured with experimental error of $5 \%$ under the load of $50 \mathrm{~g}$. The fracture surface of the specimen failed under an uniaxial tension was investigated using the high resolution scanning electron microscope.

\section{Results and discussion}

The thermographs of samples $\mathrm{Fe}_{65.9} \mathrm{Cr}_{11.6} \mathrm{Si}_{7.5} \mathrm{~B}_{15}$ and $\mathrm{Co}_{43} \mathrm{Ta}_{5.5} \mathrm{Fe}_{20} \mathrm{~B}_{31.5}$ measured at the heating rate of $20 \mathrm{~K} / \mathrm{min}$ are shown in Fig. 1. The results of the
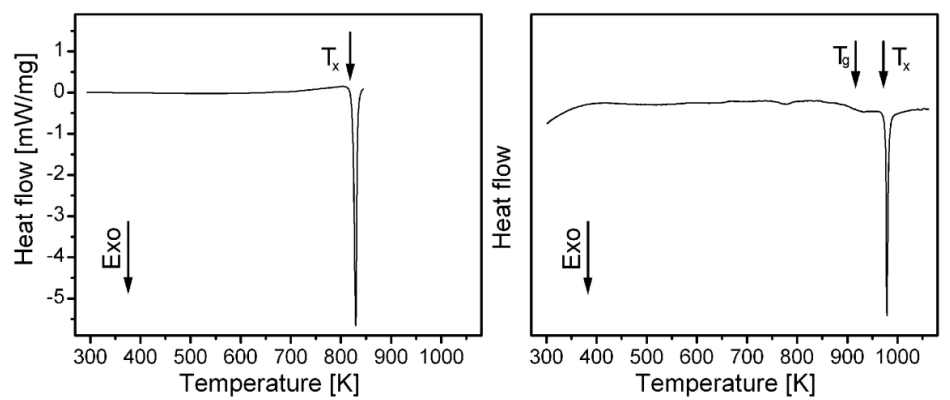

Fig. 1. DSC trace of $\mathrm{Fe}_{65.9} \mathrm{Cr}_{11.6} \mathrm{Si}_{7.5} \mathrm{~B}_{15}$ and DTA record of $\mathrm{Co}_{43} \mathrm{Ta}_{5.5} \mathrm{Fe}_{20} \mathrm{~B}_{31.5}$.

thermoanalytical characterization of samples as well as measured Vickers microhardness $H v$, the average width of dimples (or the wavelength of the vein features) $d$ on fracture surface and the estimated fracture stress $\sigma_{\mathrm{f}}$ are summarized in Table. Based on the microhardness, the tensile yield strength $\sigma_{y}$ (for ultrahigh strength glasses $\left.\sigma_{y} \approx \sigma_{\mathrm{f}}[3]\right)$ was estimated as 4 and $5 \mathrm{GPa}$ (see Table). The fractographic

TABLE

Measured values of $T_{\mathrm{g}}, T_{x}, H v, d$ and determined $\sigma_{\mathrm{f}}$.

\begin{tabular}{c|c|c|c|c|c}
\hline \hline Alloy & $T_{\mathrm{g}}[\mathrm{K}]$ & $T_{x}[\mathrm{~K}]$ & $H v$ & $d[\mu \mathrm{m}]$ & $\sigma_{\mathrm{f}}[\mathrm{GPa}]$ \\
\hline $\mathrm{Co}_{43} \mathrm{Ta}_{5.5} \mathrm{Fe}_{20} \mathrm{~B}_{31.5}$ & 912 & 980 & 1458 & 0.04 & $\approx 5$ \\
$\mathrm{Fe}_{65.9} \mathrm{Cr}_{11.6} \mathrm{Si}_{7.5} \mathrm{~B}_{15}$ & - & 819 & 1280 & 0.35 & $\approx 4$
\end{tabular}

observations have shown that the failure surface for both the samples has a ductile morphology created by meniscus instability processes. The chevron pattern morphology and the massive river relief with dimple structure manifestations were typical of Fe-based ribbons as Fig. 2a shows. Individual chevrons propagated by multiple shear band intersections are covered by the vein pattern. Figure $2 \mathrm{~b}$ shows the detail of the flat failure river-like bifurcate fracture surface with small network cellular morphology. The average cell size $d$ is $350 \mathrm{~nm}$. The high strength Co-based 
amorphous alloys are already fragile in as-quenched state at room temperature. This is illustrated with the cleavage-like behaviour in the fracture mode as can be seen in Fig. 3a. The detail of ripples in Fig. 3b shows very fine cells with typical size $d=40 \mathrm{~nm}$. The tensile fracture strength was estimated according to $H v=3 \sigma_{y}[5]$.

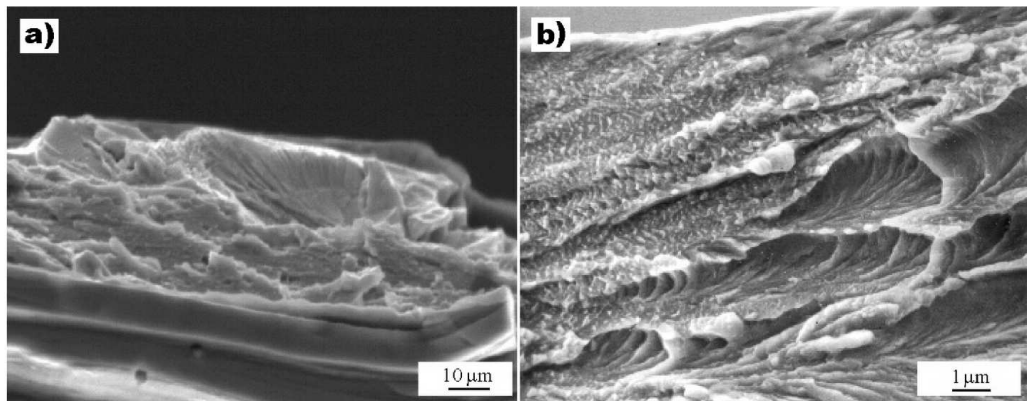

Fig. 2. Fracture morphology of Fe-ribbon (a) and a detail of chevrons (b).

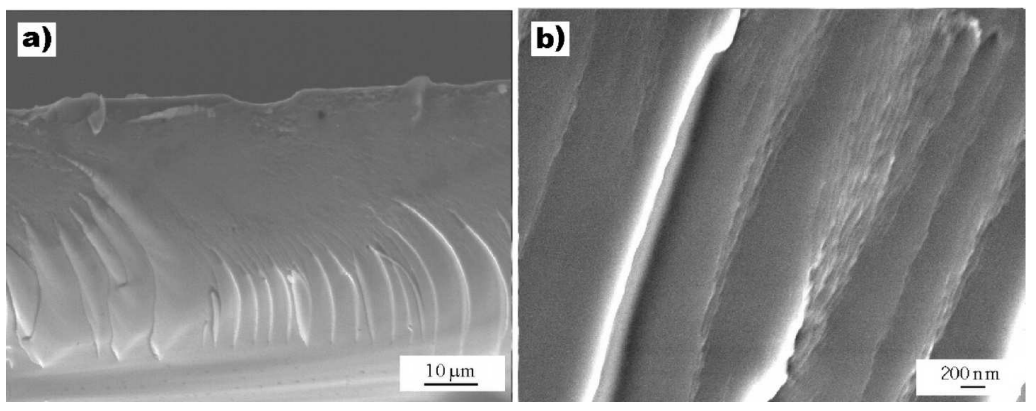

Fig. 3. Ripples on the fracture surface of the Co-based ribbon (a) with a detail of $\mathrm{nm}$ scaled cells (b).

From the macroscopic point of view the deformation is highly localized into thin shear bands. Due to the high accumulated energy in these bands, structural changes associated with a heat generation [6] and a dramatic viscosity decrease occur and therefore the final ductile fracture morphology has high local plasticity $[7,8]$. The plastic zone size and the fracture toughness are highly correlated. A plastic zone size can be estimated as follows [9]:

$$
w=\frac{1}{6 \pi}\left(\frac{K_{\mathrm{c}}}{\sigma_{f}}\right)^{2},
$$

where $w$ is the average critical plastic zone size, $K_{\mathrm{c}}$ is the fracture toughness and $\sigma_{\mathrm{f}}$ represents the fracture strength. Xi et al. [9] have supposed that the value of dimple size $d$ corresponds to the plastic zone size $w$. From the measured mean 
value of $d$ we estimated the fracture toughness $K_{\mathrm{c}}$ as 4 and $10 \mathrm{MPa} \sqrt{m}$ for the Co- and Fe-based amorphous soft magnetic ribbon, respectively. Such values are typical of very brittle metallic glasses $[8,9]$.

\section{Summary}

Fractographic analysis of Co- and Fe-based soft magnetic ribbons has shown that the ductile morphology and the massive river relief have dimple structure manifestations. The sub- $\mu$ m-scaled dimple structure in the fracture surface of the brittle glasses illustrates very high local plasticity.

\section{Acknowledgments}

The work was supported by the Slovak Grant Agency for Science - VEGA.

\section{References}

[1] S. Roth, M. Stoica, J. Degmova, U. Gaitzsch, J. Eckert, L. Schultz, J. Magn. Magn. Mater. 304, 192 (2006).

[2] Y.F. Li, M. Vazquez, D.X. Chen, J. Phys. D, Appl. Phys. 37, 389 (2004).

[3] A. Inoue, B.L. Shen, H. Koshiba, H. Kato, A.R. Yavari, Acta Mater. 52, 1631 (2004).

[4] A. Inoue, B.L. Shen, C.T. Chang, Intermetallics 14, 936 (2006).

[5] H. Men, S.J. Pang, T. Zhang, Mater. Sci. Eng. A 449-451, 538 (2007).

[6] J.J. Lewandowski, A.L. Greer, Nature Mater. 5, 15 (2006).

[7] V.Z. Bengus, E.D. Tabachnikova, J. Miškuf, K. Csach, V. Ocelík, W.L. Johnson, V.V. Molokanov, J. Mater. Sci. 35, 4449 (2000).

[8] Ch.A. Schuh, T.C. Hufnagel, U. Ramamurty, Acta Mater. 55, 4067 (2007).

[9] X.K. Xi, D.Q. Zhao, M.X. Pan, W.H. Wang, Y. Wu, J.J. Lewandowski, Phys. Rev. Lett. 94, 125510 (2005). 